\title{
Two-year follow-up status of emergency department patients with chest pain: Was it panic disorder?
}

\author{
Richard P. Fleet, MD, PhD; ${ }^{* \dagger}$ Kim L. Lavoie, $\mathrm{PhD} ;{ }^{* \dagger \S}$ Jean-Pierre Martel, $\mathrm{PhD} ; \dot{\ddagger}$ Gilles Dupuis, PhD; $;$ \\ André Marchand, PhD; $;$ Bernard D. Beitman, MD ${ }^{\mathbb{I}}$
}

See also Commentary, page 237.

\begin{abstract}
Objectives: We previously reported that 25\% (108/441) of consecutive patients presenting to the emergency department (ED) of the Montreal Heart Institute with a chief complaint of chest pain suffered from panic disorder (PD). The purpose of the present study was to re-examine these patients (with and without PD) 2 years after their initial ED visit to determine their psychiatric and psychosocial status.

Methods: An interviewer, who was kept blind to patients' initial medical and psychiatric diagnoses, attempted to contact all patients who participated in the initial study by phone. Patients who completed the phone interview were sent a battery of psychological questionnaires by mail. Results: A total of 301 (70\%) patients completed the phone interview, and 228 (52\%) patients completed the self-report questionnaires. Participants and non-participants did not differ with respect to age, gender, initial self-report scores, or initial cardiac or psychiatric diagnoses. At follow-up, significantly $(p<0.05)$ more PD+ than non-PD (PD-) patients reported: 1$)$ chest pains in the last month $(57 \%$ vs. $31 \%) ; 2$ ) one or more ED consultations in the past year for chest pain ( $40 \%$ vs. $14 \%)$; 3 ) one or more hospitalizations in the past year (31\% vs. $11 \%)$; and 4 ) perceiving their general health as "poor" ( $22 \%$ vs. $9 \%)$. PD+ patients displayed a significant $(p<0.05)$ worsening of their panic symptoms, agoraphobic avoidance, depression, and trait anxiety, and reported significantly $(p<0.05)$ greater suicidal ideation compared to PD- patients $(32 \%$ vs. $9 \%)$. Of all PD+ patients, only $22 \%$ (18/82) reported receiving some form of mental health treatment for their symptoms.

Conclusions: Unrecognized and untreated PD has a chronic and disabling course. Greater efforts should be made to screen for PD in patients complaining of chest pain in EDs.
\end{abstract}

Key words: panic disorder, chest pain, emergency department, outcome

\begin{abstract}
RÉSUMÉ
Objectifs : Dans un article antérieur, nous avons signalé que $25 \%$ (108/441) des patients consécutifs reçus à l'urgence de l'Institut de cardiologie de Montréal dont la raison de consultation était une douleur thoracique souffraient d'un trouble panique (TP). La présente étude avait comme objectif de réexaminer ces patients (avec et sans TP) deux ans après leur visite initiale à l'urgence afin de déterminer leur statut psychiatrique et psychosocial.

Méthodes: Un enquêteur à qui les diagnostics médicaux et psychiatriques initiaux des patients ne furent pas révélés, tenta de contacter par téléphone tous les patients ayant participé à l'étude initiale. Les patients ayant répondu à l'entrevue téléphonique reçurent une batterie de questionnaires psychologiques par la poste.
\end{abstract}

\footnotetext{
From the *Research Center, Montreal Heart Institute, Montréal, Que., the tDepartment of Psychiatry, Sacré-Coeur Hospital, Montréal, the ‡Department of Psychology, University of Quebec at Montreal, Montréal, the §Department of Psychology, Concordia University, Montréal, and the IDepartment of Psychiatry and Neurology, University of Missouri-Columbia, Columbia, Missouri
}

Received: Jan. 24, 2003; final submission: May 5, 2003; accepted: May 11, 2003

This article has been peer reviewed.

Can J Emerg Med 2003;5(4):247-54 
Résultats : Au total, 301 patients $(70 \%)$ répondirent à l'entrevue téléphonique et 228 patients (52\%) répondirent aux questionnaires d'auto-évaluation envoyés par la poste. II n'y avait pas de différence entre les participants et les non-participants quant à l'âge, le sexe, les scores initiaux d'auto-évaluation et les diagnostics cardiaques ou psychiatriques initiaux. Lors du suivi, un nombre significativement plus important de patients TP+ $(p<0,05)$ que de patients sans TP (TP-) signala : 1) une douleur thoracique au cours du dernier mois (57 \% vs $31 \%$ ) 2) une ou plusieurs consultations à l'urgence au cours de la dernière année pour une douleur thoracique (40\% vs $14 \%$ ) 3) une hospitalisation ou plus au cours de la dernière année (31\% vs $11 \%$ ) et 4 ) la perception de leur état de santé général comme étant «mauvais» (22\% vs $9 \%$ ). Parmi tous les patients TP+, seulement $22 \%(18 / 82)$ indiquèrent avoir reçu une certaine forme de traitement psychiatrique pour leurs symptômes.

Conclusions : Non reconnu et non traité, le trouble panique suit un cours chronique et invalidant. De plus grands efforts devraient être déployés pour identifier les patients atteints d'un trouble panique qui se plaignent d'une douleur thoracique à l'urgence.

\section{Introduction}

Chest pain is one of the most common symptoms prompting presentation to emergency departments (EDs). ${ }^{1,2}$ However, most chest pain patients do not have a clear cardiac cause for their symptoms..$^{3-8}$ We previously reported that $25 \%$ ( $n=108 / 441)$ of consecutive patients presenting to the ED of the Montreal Heart Institute with a chief complaint of chest pain met Diagnostic and Statistical Manual of Mental Disorders (DSM), 3rd ed, revised (DSM-III-R) ${ }^{9}$ criteria for panic disorder (PD). ${ }^{10} \mathrm{PD}$ is characterized by recurrent panic attacks that consist of sudden episodes of intense fear or discomfort associated with several cognitive and somatic symptoms. Six of the 13 diagnostic symptoms of a panic attack are also cardinal features of cardiovascular diseases: chest pain, palpitations, sweating, shortness of breath, sensation of choking, and hot flushes. ' (See Table 1 for a summary of diagnostic criteria.)

Studies suggest that the overall prevalence of PD in patients with non-cardiac (i.e., with either normal angiograms or normal scintigraphic tests) chest pain lies between $34 \%$ and $56 \% .^{11-13}$ This makes PD 30 to 50 times more common in non-cardiac chest pain patients than in the overall population. ${ }^{14}$

PD is a serious, debilitating anxiety disorder that if left untreated often has a chronic course and may lead to the development of other psychiatric conditions such as agoraphobia, depression and substance abuse disorders. ${ }^{13-18}$ Despite the apparent psychological and psychosocial distress exhibited by these patients, most panic disorder patients go undetected/unreported by physicians. ${ }^{19,20}$ We previously reported that $98 \%$ (106/108) of PD diagnoses go unrecognized by emergency cardiologists in a specialized chestpain assessment unit. ${ }^{10}$ Hence, PD is both a common and highly distressing condition among chest pain patients. However, because PD is rarely detected or diagnosed in the cardiology and ED setting, ${ }^{10,19,20}$ the long-term psychiatric and psychosocial prognosis of these patients remains largely unexplored.

The purpose of the present study was to examine the psychiatric and psychosocial status of chest pain patients who met diagnostic criteria for PD 2 years after their initial ED consultation, and to compare their psychosocial status with that of chest pain patients not meeting diagnostic cri-

\section{Table 1. Diagnostic features of panic disorder according to DSM-III-R and DSM-IV criteria}

\section{Panic disorder:}

1. Recurrent unexpected panic attacks (see below)

2. Persistent concern about having additional attacks, including worry about the implications of attack or its consequences

3. Significant change in behaviour as a result of the attacks

\section{Panic attack:}

A discrete period of intense fear or discomfort in which 4 or more of the following symptoms develop abruptly and reach a peak within 10 minutes.

1. Palpitations or accelerated heart rate

2. Sweating

3. Trembling or shaking

4. Shortness of breath (dyspnea)

5. Choking

6. Chest pain or discomfort

7. Nausea or abdominal discomfort

8. Feeling dizzy, unsteady or faint

9. Numbness or tingling sensations (paresthesias)

10. Chills or hot flashes

11. Derealization (feelings of unreality) or depersonalization (being detached from oneself)

12. Fear of losing control or going crazy

13. Fear of dying

DSM-III-R = Diagnostic and Statistical Manual of Mental Disorders, 3rd ed rev, 1987

DSM-IV = Diagnostic and Statistical Manual of Mental Disorders, 4th ed, 1994 
teria for PD. Follow-up of these patients would help clarify whether PD patients who seek treatment in an ED are at risk for long-term psychosocial disability.

\section{Methods}

\section{Patients}

The Montreal Heart Institute's Scientific and Ethics Committees approved the research protocol. Written informed consent was obtained from eligible patients. The initial sample consisted of 441 consecutive patients presenting to the ED of the Montreal Heart Institute with a chief complaint of chest pain. Diagnostic interviews conducted between February 1993 and June 1994 determined that 25\% ( $n=108)$ of the total sample met DSM-III-R criteria for PD (with or without agoraphobia). The DSM-III-R was the latest version of the DSM available at the time of the initial study, and diagnostic criteria from DSM-III-R and DSMIV have essentially remained unchanged. ${ }^{21}$

An average of 2 years after their initial ED consultation visit (between May 1996 and December 1996), attempts were made to contact all patients by telephone and by mail. A total of 301 patients completed the phone interview (representing $70 \%$ of the initial sample) and were mailed the battery of self-report questionnaires; 228 of the 301 patients completed and returned the questionnaires (representing $52 \%$ of the initial sample).

\section{Study site}

The Montreal Heart Institute is a teaching hospital affiliated with the University of Montreal's Faculty of Medicine; it specializes in cardiac care. The ED is currently staffed with both emergency physicians and cardiologists and is open to anyone who presents with potential cardiac symptoms. However, at the time the study was conducted, cardiologists $(n=30)$ exclusively staffed the ambulatory (walk-in) ED section on a rotating schedule of approximately 1 week per year.

\section{Measures}

Assessment for sampling bias: A series of one-way analyses of variance (ANOVAs) were conducted to evaluate whether subject loss for the follow-up phase of the study was biased or random. Variables of interest included participants' and non-participants' baseline age, gender, self-report scores, and cardiac and psychiatric diagnoses.

Phone interview: All patients were contacted by phone an average of 23 months (range 11-39 mo; standard deviation [SD] 5.4) after their initial ED visit for a 15- to 20-minute phone interview. The interview protocol consisted of 40 questions modified from Beitman and colleagues ${ }^{15}$ that pertained to the following 9 categories: 1) experience of chest pain in the past month; 2) number of medical consultations and hospitalizations for chest pain in the past year; 3) number of ED visits for chest pain in the past year; 4) perceived cause for chest pain symptoms; 5) work disability resulting from chest pain symptoms; 6) perceived health status; 7) suicidal ideation; 8) mental health treatment; and 9) psychotropic medication.

The interviewer was a trained doctoral-level graduate student in clinical psychology who was blind to each patient's initial medical and psychiatric diagnoses, as well as to the specific hypotheses of the study.

Self-report questionnaires: At the end of the phone interview, patients were asked to complete a series of self-report questionnaires, which were mailed to them shortly after the interview. All questionnaires are widely used in research and clinical practice and display good to excellent psychometric properties. The Panic-Agoraphobia scales selected came highly recommended by a group of leading panic researchers as essential instruments to use in studies examining panic. ${ }^{22}$ All questionnaires were identical to those completed during their initial ED visit and take between 20 and 45 minutes to complete. The complete battery of tests was as follows: Panic-Agoraphobia: Agoraphobia Cognitions Questionnaire (ACQ) ${ }^{23}$ Mobility Inventory for Agoraphobia (MIA), ${ }^{24}$ Body Sensations Questionnaire (BSQ) ${ }^{23}$ Anxiety: State-Trait Anxiety Inventory (STAI), ${ }^{25}$ and Depression: Beck Depression Inventory (BDI). ${ }^{26}$

Probability of panic disorder diagnosis at follow-up: To examine the probability that PD patients identified during the initial ED consultation would still meet criteria for PD at follow-up, scores on the ACQ and MIA and the sensory subscale of the Short-Form McGill Pain Questionnaire ${ }^{27}$ (not presented here; for a detailed description see reference 10) were entered into the Montreal Heart Panic Model. ${ }^{28}$ This logistic regression model correctly classifies $84 \%$ of chest pain patients into "PD" and "no PD" categories with a sensitivity of 59\% and specificity of $93 \%{ }^{28}$ Others have recently revalidated this model in an outpatient cardiology chest pain population, correctly classifying $78 \%$ of 199 patients into PD and no PD categories with a sensitivity of $58 \%$ and specificity of $81 \% .{ }^{29}$

\section{Analyses}

PD and non-PD patients' dichotomous measures obtained during the phone interview were analyzed using chi-squared procedures. PD and non-PD patients' follow-up measures on 
the self-report questionnaires were analyzed using one-way ANOVAs. To examine the course of PD over 2 years, analyses of PD patients' baseline and follow-up measures on the self-report questionnaires were conducted using repeated measures ANOVAs. Level of significance was set at $p<0.05$.

\section{Results}

\section{Patient characteristics}

The 2 study groups were classified as having PD (PD+) or not having PD (PD-) according to whether they met DSMIII-R diagnostic criteria for PD at the time of their initial ED consultation. Of the 301 patients who completed the phone interview, a total of 82 patients were classified as PD+ and 219 patients were classified as PD-. Of these patients, $61 \%$ were male and had a mean age of 56.9 (SD $11.5)$ years. Of the 228 patients who completed the self-report questionnaires, 60 were classified as PD+ and 168 were classified as PD-. Of these patients, $61 \%$ were male and had a mean age of $56.7(\mathrm{SD}=11.4)$ years (Table 2$)$. A complete description of the initial sample's information is provided elsewhere. ${ }^{10}$ Noteworthy is that $145(47.4 \%)$ who completed the phone interview had a documented history of coronary artery disease (CAD) (documented past myocardial infarction, positive angiographic study, percutaneous transluminal coronary recanalization or coronary artery bypass graft). Of these, $31 / 145$ were in the PD+ group and 114/145 in the PD- group. Initial discharge chest pain diagnoses were obtained for 89\% (267/301) of patients reached by phone. One hundred patients were diagnosed with typical angina pain (37\%), 167 patients $(63 \%)$ with non-cardiac chest pain. Eighty-one percent of

\begin{tabular}{|c|c|c|}
\hline Variable & $\begin{array}{l}\text { Phone } \\
\text { interview }\end{array}$ & $\begin{array}{c}\text { Self-report } \\
\text { questionnaire }\end{array}$ \\
\hline \multicolumn{3}{|l|}{ Study groups* } \\
\hline PD+, no. & 82 & 60 \\
\hline PD-, no. & 219 & 168 \\
\hline Age, yr (and SD) & $56.9(11.5)$ & $56.7(11.4)$ \\
\hline Males, no. (and \%) & $184(61)$ & $139(61)$ \\
\hline Living alone, no. (and \%) & $93(31)$ & $68(30)$ \\
\hline Unemployed, no. (and \%) & $166(55)$ & $130(57)$ \\
\hline $\begin{array}{l}\text { High school education or } \\
\text { less, no. (and \%) }\end{array}$ & $205(68)$ & $157(69)$ \\
\hline \multicolumn{3}{|c|}{$\begin{array}{l}\text { *Patients were classified according to whether they met DSM-III-R diagnostic } \\
\text { criteria for panic disorder (PD) at the time of their initial emergency department } \\
\text { consultation. } \\
\text { DSM-III-R = Diagnostic and Statistical Manual of Mental Disorders, 3rd ed rev, } \\
1987 \\
\text { PD+ = Patients classified as having panic disorder; PD- = patients classified as not } \\
\text { having panic disorder, according to criteria described above. }\end{array}$} \\
\hline
\end{tabular}

patients with $\mathrm{PD}+(n=58)$ were discharged with a diagnosis of non-cardiac chest pain.

\section{Assessment for sampling bias}

Due to the relative degree of subject loss from the initial study to follow-up, we compared patients who completed both the follow-up interview and questionnaires $(n=228)$ to those from the initial sample who did not $(n=213)$ using baseline data obtained during their initial ED visit. These comparisons revealed no significant differences between participants and non-participants with respect to baseline age, gender, self-report questionnaire scores, psychiatric diagnoses or cardiac diagnoses. Subject loss from baseline to follow-up was therefore determined to be random.

\section{Follow-up status}

Phone interview: We found significant differences between PD+ and PD- on several measures of psychosocial disability (Table 3). Significantly more PD+ than PD- patients reported 1) experiencing chest pain in the past month, 2) at least one or more ED consultations in the past year and 3) at least 1 or more hospitalizations in the past year. A greater proportion of PD+ than PD- patients judged their general health as poor and reported having suicidal ideation in the past week. Finally, despite their apparent disability and distress, just over $20 \%$ of PD+ patients reported receiving some form of mental health treatment, although significantly more PD+ than PD- patients were taking anti-anxiety medication (benzodiazepines) at the time of the follow-up interview.

Self-report questionnaires: At follow-up, PD+ patients continued to exhibit significantly higher panic-agoraphobia, state and trait anxiety, as well as depression scores than PD- patients (Table 4). However, it is noteworthy that both groups of patients showed increases on these scales from baseline (Figs. 1-3).

Probability of PD diagnosis at follow-up: At follow-up, 57 of the $60 \mathrm{PD}+$ patients who completed the self-report questionnaires screened positive for PD using the Montreal Heart Panic Model previously described. This suggests that 97\% of patients meeting diagnostic criteria for PD during their initial ED consultation probably still met diagnostic criteria for PD at follow-up.

\section{Discussion}

This study examined the psychosocial status of chest pain patients who met DSM-III-R diagnostic criteria for panic 
disorder, an average of 2 years after their initial ED consultation, and compared their functioning with that of chest pain patients not meeting diagnostic criteria for panic disorder in the ED. The results showed that compared to PDpatients, a significantly greater proportion of $\mathrm{PD}+$ patients reported continued chest pains, nearly 4 times as many ED visits for chest pain, and nearly 3 times as many cardiac hospitalizations. Moreover, PD+ patients exhibited significantly greater psychological distress and judged their general health as poor relative to PD- patients.

Table 3. Psychosocial disability in patients with (PD+) and without (PD-) panic disorder, as reported by patients during phone interview

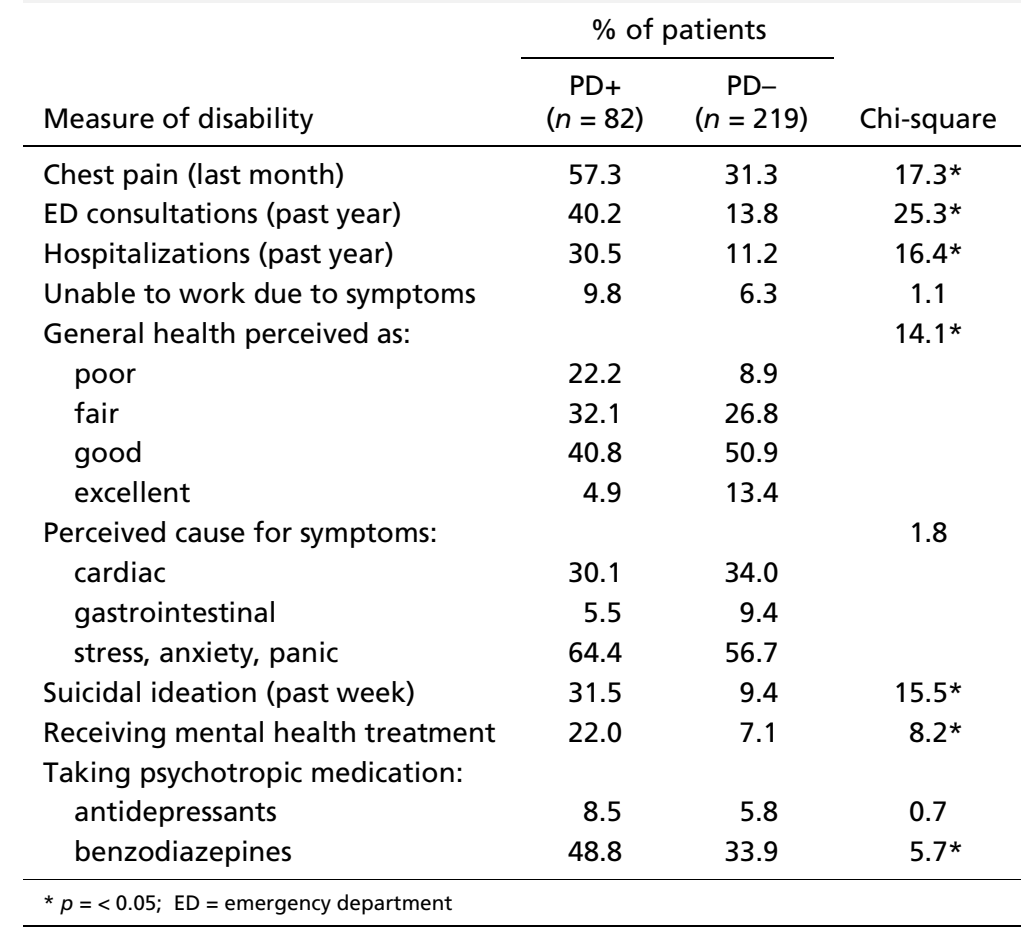

Table 4. Means and standard deviations (SDs) calculated from responses on self-report questionnaires done by patients with (PD+) and without (PD-) panic disorder

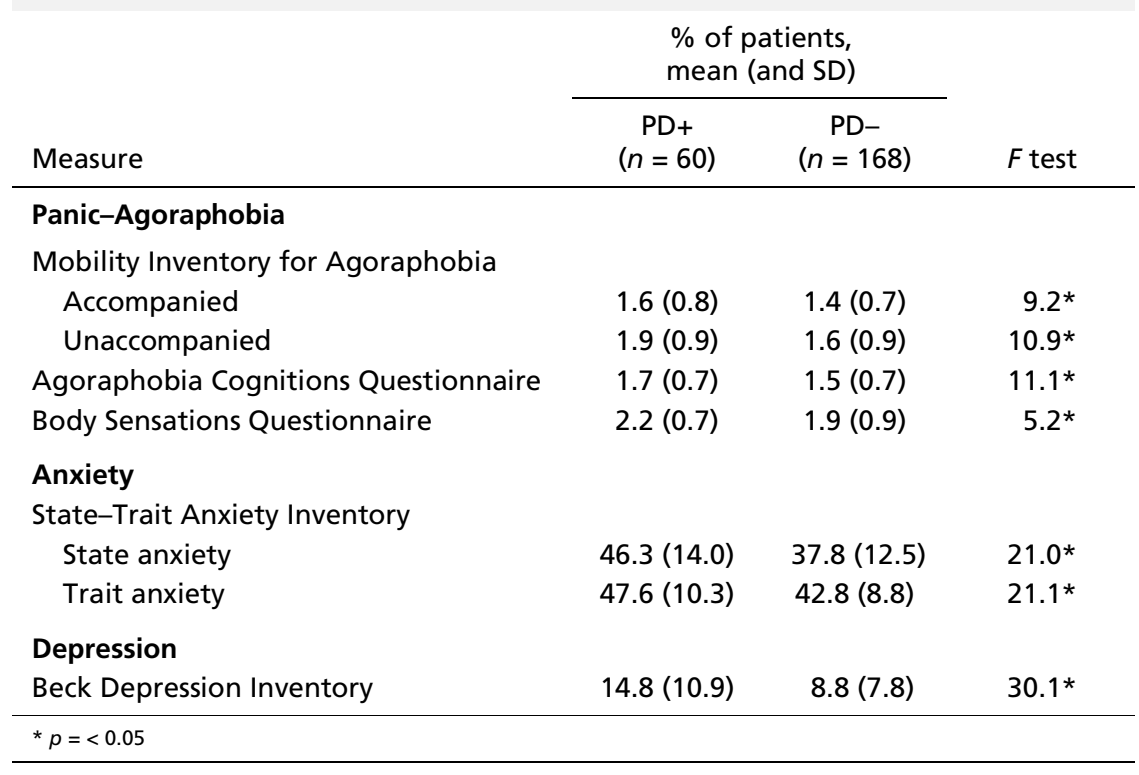


These findings are consistent with those reported by Beitman and colleagues, who examined $36 \mathrm{PD}+$ and 36 PD- chest pain patients, an average of 3 years after angiographic testing. ${ }^{15}$ At follow-up, significantly more PD+ patients experienced chest pain and viewed their general health as poor relative to $\mathrm{PD}-$ patients. Our results are also similar to those of Roy-Byrne and colleagues, who found that at a follow-up of 4-10 months, significantly more PD+ than PD- patients demonstrated an inability to work, more frequent ED and outpatient physician visits, and higher hospitalization rates. ${ }^{16}$ Our results are also comparable to epidemiological studies reporting that PD+ versus PD- patients make more medical visits and are disproportionally represented among distressed, high health care utilizers. ${ }^{31-33}$ Taken together, the results of these studies are highly consistent and underline the negative prognostic consequences of $\mathrm{PD}$ in $\mathrm{ED}$, cardiology and primary care patients.

At follow-up, PD+ patients also exhibited greater psychological distress, as evidenced by their higher scores on all self-report measures. Compared to PD- patients, PD+

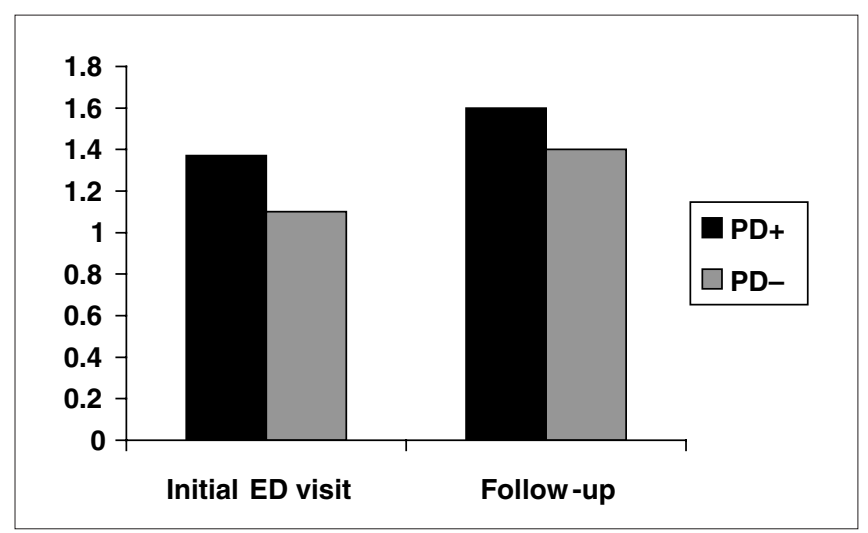

Fig. 1. Mobility Inventory for Agoraphobia (MIA)-Unaccompanied scores for patients at base-line and at 2-year followup. See Results section for definitions of PD+ and PD-.

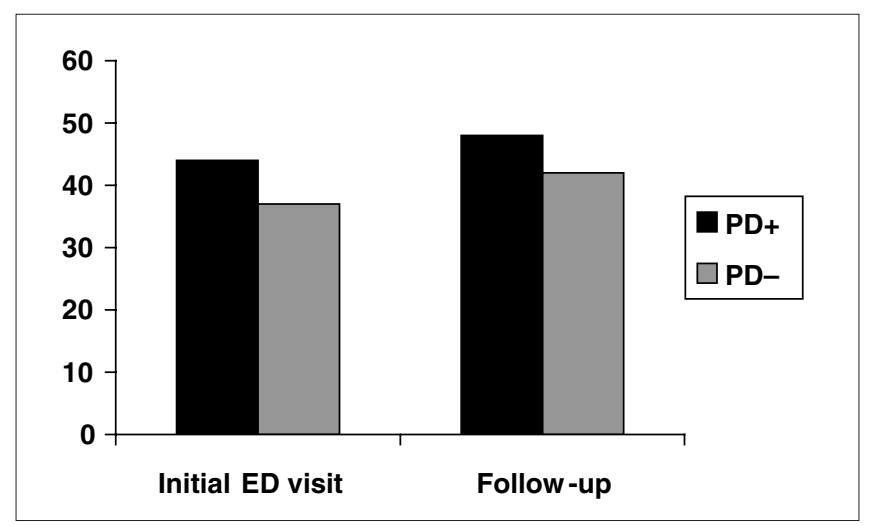

Fig. 2. State-Trait Anxiety Inventory scores for patients at baseline and at 2-year follow-up. patients reported experiencing significantly greater agoraphobic avoidance (ACQ, MIA-A [MIA-Accompanied], MIA-U [MIA-Unaccompanied]), panic symptoms (BSQ), anxiety symptoms (STAI), and depression (BDI). These findings are also consistent with those reported by Beitman and colleagues,,$^{15}$ who found that at follow-up, PD+ patients reported experiencing significantly more anxiety symptoms (as measured by the Zung Self-Rating Anxiety Scale), social dysfunction (as measured by the Social Adjustment Scale) and general psychological distress (as measured by the Brief Symptom Inventory) compared to PD- patients.

Perhaps, the most disturbing psychological finding is the proportion of PD+ patients reporting suicidal ideation in the week preceding the completion of the follow-up questionnaires. A remarkable $31 \%$ of PD+ versus $9 \%$ of PDpatients reported having suicidal thoughts in the 7 days prior to the follow-up assessment. We have previously reported that in our original sample, the proportion of PD+ versus PD- patients reporting having suicidal ideation during the week preceding their ED visit was $25 \%$ and $5 \%$ respectively $(p<0.0001)$. This finding remained significant even after controlling for co-morbid major depression. ${ }^{10}$ Suicidal ideation is a risk factor of actual suicide, along with male gender, age over 40 years, a mental disorder as well as a recent visit to a doctor, which were all characteristics of our PD patients.

Although we did not submit patients to a structured diagnostic interview at follow-up, we did estimate the probability that PD+ patients would still meet diagnostic criteria for PD using the Montreal Heart Panic Model. This model has been used and cross-validated by others. ${ }^{28,29}$ Using this model, we estimated that 57 of $60 \mathrm{PD}+$ patients (97\%) still met diagnostic criteria for PD at follow-up. This is consistent with findings reported by Roy-Byrne and colleagues, who found (using a structured diagnostic interview) that as

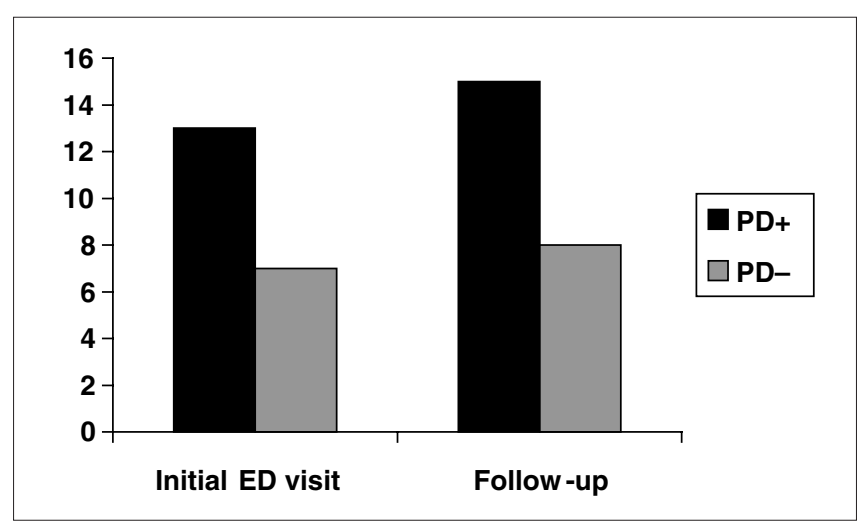

Fig. 3. Beck Depression Inventory scores for patients at baseline and at 2-year follow-up. 
many as $85 \%$ of their sample of PD+ patients still met DSM-IV criteria for PD at the time of their follow-up (410 months) assessment. ${ }^{16}$ Thus, our results highlight both the stability and progression of PD diagnoses over time.

How can we explain PD+ patients' apparent psychosocial and psychological deterioration at follow-up? It could be in part explained by the finding that remarkably few (22\%) PD+ patients were actually undergoing or had received some form of mental health treatment for their symptoms at the time of the follow-up assessment. This is identical to the findings reported by Beitman and colleagues. ${ }^{15}$ Left untreated, PD has been shown to have a chronic, disabling course. Patients with PD may also develop other psychiatric conditions, such as agoraphobia, social phobia and major depressive disorder, which may further complicate PD outcome. ${ }^{18,20,30}$

Moreover, the finding that few PD+ patients were undergoing or receiving some form of recognized effective treatment for PD could be in part be explained by the fact that patients were not specifically diagnosed as having PD at the time of their initial ED visit. Previous research suggests that PD patients are rarely recognized or diagnosed by physicians. ${ }^{19,20,34}$ Rates of physician non-recognition of PD are reported to be as high as $61 \%$ in primary care ${ }^{34}$ and $98 \%$ in EDs. ${ }^{10}$ Other reports have shown that even when anxiety is recognized in the primary care or ED setting, treatment is either not forthcoming or inadequate. ${ }^{35}$ Nonrecognition of PD by ED physicians can be in part explained by the fact that these physicians are confronted by large numbers of patients with potentially life-threatening illnesses, such as CAD, that must first be carefully excluded, before attending to non-immediate life-threatening although distressful, mental disorders like PD.

At follow-up, the majority (49\%) of PD+ patients who had been prescribed psychotropic medication for their panic symptoms were taking a benzodiazepine (anxiolytics). However, given their continued psychosocial distress, these medications appeared to be doing little to alleviate patients' panic symptoms over the follow-up period. This is not surprising considering the fact that benzodiazepines are typically prescribed to treat panic symptoms once they emerge and do little to treat patients' underlying propensity to experience panic symptoms.

Fortunately, PD is a condition that has been shown to be highly treatable using antidepressant pharmacotherapy, psychotherapy, or some combination of both. ${ }^{30-33}$ Recent research indicates that the newer class of antidepressants, called selective serotonin reuptake inhibitors (SSRIs), are fast emerging as the pharmacotherapy of choice for the treatment of panic disorder. ${ }^{33-36}$ Unlike benzodiazepines, they do not have addictive properties. Of particular interest to physicians treating panic disorder in cardiac patients is that they have been shown to be relatively safe when used in conjunction with other cardiac medications and have little or no cardiotoxic side effects. ${ }^{37}$

\section{Study limitations}

First, this study is limited by the fact that there was no medical follow-up. Although it would have been interesting to examine the course and outcome of initial chest pain and cardiac diagnoses, this was not the focus of the study.

A second limitation of the present study was that only $52 \%$ of the initial sample completed and returned the psychological questionnaires. However, our assessment of sampling bias revealed no significant differences between follow-up participants and non-participants with respect to age, gender, initial self-report scores, and both psychiatric and cardiac diagnoses. We therefore conclude that subject attrition was random and not due to any meaningful differences between participants and non-participants.

Finally, another limitation is the fact that we did not readminister a structured diagnostic interview to confirm PD status at follow-up. However, we did estimate the probability of having PD at follow-up using a validated detection model. Coupled with the continued psychosocial distress exhibited by $\mathrm{PD}+$ patients relative to $\mathrm{PD}$ - patients, we are confident that patients estimated to have PD+ at follow-up likely did.

\section{Conclusion}

Taken together, the results of the present study suggest that unrecognized and untreated PD has a chronic, disabling and distressing course. Thus, PD patients who seek treatment in an ED may indeed be at increased risk for longterm disability and psychosocial malfunctioning. Greater resources need to be devoted to the early detection, diagnosis, and treatment of patients with PD in the ED and related medical settings. This task may be difficult to accomplish for often-overburdened ED physicians, dealing with more potentially life-threatening diseases. Nevertheless, given the frequency of PD in ED patients, it is important that emergency physicians build networks with community physicians and local mental health providers to allow for the timely and appropriate care for these patients. Priority should be given to patients with chest pain not fully explained by their cardiac status that also have a history of repeated visits for similar symptoms.

Competing interests: None declared. 


\section{References}

1. Karlson BW, Herlitz J, Pettersson P, Ekvall HE, Hjalmarson A. Patients admitted to the emergency room with symptoms indicative of acute myocardial infarction. J Intern Med 1991;230:251-8.

2. Kroenke K, Mangelsdorff AD. Common symptoms in ambulatory care: incidence, evaluation, therapy, and outcome. Am J Med 1989;86:262-6.

3. Lee TH, Cook EF, Weisberg M, Sargent RK, Wilson C, Goldman L. Acute chest pain in the emergency room: identification and examination of low-risk patients. Arch Intern Med 1985; 145:65-9.

4. Lavey EB, Winkle RA. Continuing disability of patients with chest pain and normal coronary arteriograms. J Chronic Dis 1979;32:191-6.

5. Papanicolaou MN, Califf RM, Hlatky MA, McKinnis RA, Harrell FE Jr, Mark DB, et al. Prognostic implications of angiographically normal and insignificantly narrowed coronary arteries. Am J Cardiol 1986;58:1181-7.

6. Wielgosz AT, Fletcher RH, McCants CB, McKinnis RA, Haney TL, Williams RB. Unimproved chest pain in patients with minimal or no coronary disease: a behavioural phenomenon. Am Heart J 1984;108:67-72.

7. Ockene IS, Shay MJ, Alpert JS, Weiner BH, Dalen JE. Unexplained chest pain in patients with normal coronary arteriograms: a follow-up study of functional status. N Engl J Med 1980;303:1249-52.

8. Tueth MJ. Managing recurrent nonischemic chest pain in the emergency department. Am J Emerg Med 1997;15:170-2.

9. Diagnostic and statistical manual of mental disorders, 3rd ed, rev (DSM-III-R). Washington (DC): American Psychiatric Association; 1987.

10. Fleet RP, Dupuis G, Marchand A, Burelle D, Arsenault A, Beitman BD. Panic disorder in emergency department chest pain patients: prevalence, comorbidity, suicidal ideation, and physician recognition. Am J Med 1996;101:371-80.

11. Beitman BD, Mukerji V, Lamberti JW, Schmid L, DeRosear L, Kushner M, et al. Panic disorder in patients with chest pain and angiographically normal coronary arteries. Am J Cardiol 1989; 63:1399-403.

12. Katon W, Hall ML, Russo J, Cormier L, Hollifield M, Vitaliano $\mathrm{PP}$, et al. Chest pain: relationship of psychiatric illness to coronary arteriographic results. Am J Med 1988;84:1-9.

13. Carter C, Maddock R, Zoglio M, Lutrin C, Jella S, Amsterdam E. Panic disorder and chest pain: a study of cardiac stress scintigraphy patients. Am J Cardiol 1994;74:296-8.

14. Kessler RC, McGonagle KA, Zhao S, Nelson CB, Hughes M, Eshleman S, et al. Lifetime and 12-month prevalence of DSM-III$\mathrm{R}$ psychiatric disorders in the United States: results from the National Comorbidity Survey. Arch Gen Psychiatry 1994;51:8-19.

15. Beitman BD, Kushner MG, Basha I, Lamberti J, Mukerji V, Bartels K. Follow-up status of patients with angiographically normal coronary arteries and panic disorder. JAMA 1991;265: 1545-9.

16. Roy-Byrne PP, Stein MB, Russo J, Mercier E, Thomas R, McQuaid J, et al. Panic disorder in the primary care setting: comorbidity, disability, service utilization, and treatment. J Clin Psychiatry 1999;60:492-9.

17. Reich J, Warshaw M, Peterson LG, White K, Keller M, Lavori $\mathrm{P}$, et al. Comorbidity of panic and major depressive disorder. J Psychiat Res 1993;27 (suppl 1):23-33.

18. Brown TA, Barlow DH. Comorbidity among anxiety disorders: implications for treatment and DSM-IV. J Consult Clin Psychol 1992;60:835-44.

19. Wulsin LR, Arnold LM, Hillard JR. Axis I disorders in ER patients with atypical chest pain. Int J Psychiatry Med 1991;21:37-46.

20. Weissman MM. The hidden patient: unrecognized panic disorder. J Clin Psychiatry 1990;51 (suppl):5-8.

21. Diagnostic and statistical manual of mental disorders, 4th ed (DSM-IV). Washington (DC): American Psychiatric Association; 1994.

22. Shear MK, Maser JD. Standardized assessment for panic disorder research. A conference report. Arch Gen Psychiatry 1994; 51:346-54.

23. Chambless DL, Caputo GC, Bright P, Gallagher R. Assessment of fear in agoraphobics: the Body Sensations Questionnaire and the Agoraphobic Cognitions Questionnaire. J Consult Clin Psychol 1984;52:1090-7.

24. Chambless DL, Caputo GC, Jasin SE, Gracely EJ, Williams C. The Mobility Inventory for Agoraphobia. Behav Res Ther 1985;23:35-44.

25. Spielberger CD. Manual for the State-Trait Anxiety Inventory (STAI form Y). Palo Alto (CA): Consulting Psychologists Press; 1993.

26. Beck AT. Depression: clinical, experimental, and theoretical aspects. New York: Harper \& Row; 1967.

27. Melzack R. The short-form McGill Pain Questionnaire. Pain 1987;30:191-7.

28. Fleet RP, Dupuis G, Marchand A, Burelle D, Beitman BD. Detecting panic disorder in emergency department chest pain patients: a validated model to improve recognition. Ann Behav Med 1997;19:124-31.

29. Dammen T, Ekeberg O, Arnesen H, Friis S. The detection of panic disorder in chest pain patients. Gen Hosp Psychiatry 1999;21:323-32.

30. Schmidt NB. Panic disorder: cognitive-behavioral and pharmacological treatment strategies. J Clin Psychol Med Settings 1999;6:89-111.

31. Dyckman JM, Rosenbaum RL, Hartmeyer RJ, Walter LJ. Effects of psychological intervention on panic attack patients in the emergency department. Psychosomatics 1999;40:422-7.

32. Zun LS. Panic disorder: diagnosis and treatment in emergency medicine. Ann Emerg Med 1997;30:92-6.

33. Nutt DJ. Antidepressants in panic disorder: clinical and preclinical mechanisms. J Clin Psychiatry 1998;59(suppl 8):24-8.

34. Yeragani VK, Jampala VC, Sobelewski E, Kay J, Igel G. Effects of paroxetine on heart period variability in patients with panic disorder: a study of Holter ECG records. Neuropsychobiology 1999;40:124-8.

35. Montgomery S, Bullock T, Fineberg N. Serotonin selectivity for obsessive compulsive and panic disorders. J Psychiatry Neurosci 1991;16 (suppl 1):30-5.

36. Bocola V, Trecco MD, Fabbrini G, Paladini C, Sollecito A, Martucci N. Antipanic effect of fluoxetine measured by $\mathrm{CO}_{2}$ challenge test. Biol Psychiatry 1998;43:612-5.

37. Sheline YI, Freedland KE, Carney RM. How safe are serotonin reuptake inhibitors for depression in patients with coronary heart disease? Am J Med 1997;102:54-9.

Correspondence to: Dr. Richard P. Fleet, Research Center, Montreal Heart Institute, 5000 Belanger St., Montréal QC H1T 1C8; 514 376-3330 x3654; fax 514 376-1355, rfleet@ videotron.ca 